Revue d'histoire de l'Amérique française

ZAS REVUE D.HISTOIRE DE L'AMÉRIQUE FRANÇAISE

\title{
Un jeune Canadien errant, en 1715
}

\section{Marc Gaucher et J. Long}

Volume 3, numéro 4, mars 1950

URI : https://id.erudit.org/iderudit/037764ar

DOI : https://doi.org/10.7202/037764ar

Aller au sommaire du numéro

Éditeur(s)

Institut d'histoire de l'Amérique française

ISSN

0035-2357 (imprimé)

1492-1383 (numérique)

Découvrir la revue

Citer ce document

Gaucher, M. \& Long, J. (1950). Un jeune Canadien errant, en 1715. Revue

d'histoire de l'Amérique française, 3(4), 492-492.

https://doi.org/10.7202/037764ar d'utilisation que vous pouvez consulter en ligne.

https://apropos.erudit.org/fr/usagers/politique-dutilisation/ 
rience, mais sur les déficiences de certains ouvrages, et ensuite parce que toutes les paroisses existent dans des conditions bien différentes les unes des autres. Tout cet exposé peut servir à faire penser, à prévenir certaines erreurs: il n'a point d'autre fin.

Marcel TRUDEL, professeur d'histoire du Canada a l'Université Laval.

\section{UN JEUNE CANADIEN ERRANT, EN 1715*}

* Voici un extrait de lettre qui explique l'origine de ce document:

"Permettez à un naturel manceau - grandi au Canada - de vous adresser une modeste trouvaille, un échantillon de Petite Histoire rencontré au hasard de patientes recherches sur l'émigration mancelle sous l'Ancien Régime via les "Isles" et le "Canada".

(SIGNE): Marc Gavcher 43 avenue Rubillard, LE MANS

Par Devant les Notres Royaux à la Rochelle, a esté présent en sa personne Louis Portelanse natif du Canada, aagé de dix sept ans ou environ, lequel s'est vollontairement engagé par les présentes au $\mathrm{S}^{\mathrm{r}}$ Jean Lelong capitaine du batteau le $S^{t}$ Bernard de la Rochelle acceptant prêt à partir pour LA Martinique pour l'aller servir ou autres le représentant en touttes choses raisonnables quy luy seront commandées pendant trois années entières et consécutives quý commenceront au moment que led. engagé mettra pied à terre aud. lieu et sera en estat de servir, durant lequel temps il sera nourry, logé, entretenu d'habits à la manière des engagés et deffrayé de son passage en allant seullement et pour y parvenir promet de s'embarquer au premier mandement dud. Lelong. Ces présentes faittes moyennant et à raison de trois sens livres de sucre pour lesd. trois années de services payable aud. engagé aud. Pays à l'expiration d'icelles par celluy ou ceux au service de quy il sera sans recours contre ledit capitaine qu'il en descharge des à présent au surplus renoncer au bénéfice de la déclaration du Roy en faveur des engagés, c'est l'intention des partyes quy a l'entretien à peine de tous despens dommages et interets obligent leurs biens, jugé et Condamné. Fait à la Rochelle estude de Soullard avant midy le treisiesme mars mil sept cent quinze et a led. engagé déclaré ne scavoir signer de ce requis.

Controllé à La Rochelle

le $21,3,1715$

Mereau

J. LoNG. 